\title{
Flexural behaviour of RC beams strengthened with wire mesh-epoxy composite
}

Ismail M.I. Qeshta, Payam Shafigh, Mohd Zamin Jumaat*

Department of Civil Engineering, Faculty of Engineering, University of Malaya, 50603 Kuala Lumpur, Malaysia

H I G H L I G H T S

- A new strengthening material for RC structures was introduced.

- Wire mesh-epoxy composites can be fabricated as a laminate.

- The structural performance of RC beams strengthened with a new laminate was studied.

A R T I C L E I N F O

Article history:

Received 30 August 201

Received in revised form 11 December 2014

Accepted 2 January 2015

Available online 21 January 2015

Keywords:

Wire mesh

Epoxy

FRP

Flexural performance

$\mathrm{RC}$ beam
A B S T R A C T

In this research work, the flexural behaviour of reinforced concrete (RC) beams strengthened with a new type of strengthening material, namely wire mesh-epoxy composite, was investigated. The flexura behaviour of RC beams strengthened using this new material was compared with RC beams strengthened with carbon fibre reinforced polymer (CFRP) sheet. In addition, the structural performance of a beam strengthened using a hybrid of wire mesh-epoxy and CFRP sheet was investigated. The results showed that the use of wire mesh-epoxy composite provides considerable enhancement in the performance of strengthened beams. Compared to CFRP, the wire mesh-epoxy strengthened beams showed more improvement in the first crack load, stiffness and yield strength. In addition, the use of hybrid wire mesh-epoxy-carbon fibre composite indicated better post-yield behaviour and prevented the debonding of the CFRP sheet.

(c) 2015 Elsevier Ltd. All rights reserved.

\section{Introduction}

The strengthening and rehabilitation of reinforced concrete (RC) structures are among the most challenging tasks in the civil engineering field. The upgrading and retrofitting of structures is a necessity for many reasons, such as increase in vehicle load, to overcome original design or detailing errors and the deterioration that occurs during the service life of structures. Over the last three decades, significant research has been documented on the use of different materials for the flexural strengthening of RC structures.

Steel plates bonded to the soffits of beams are among the earliest materials adopted and investigated $[1,2]$. Despite the improvement in flexural capacity, stiffness and cracking behaviour of the strengthened beams, the use of steel plates has shown some draw backs, such as the corrosion of steel and the difficulties of transportation and handling of long plates [3-5]. In order to resolve the

* Corresponding author. Tel.: +60 379675203; fax: +60 379675318.

E-mail addresses: ismailqeshta@siswa.um.edu.my, ismailqeshta@gmail.con (I.M.I. Qeshta), pshafigh@gmail.com (P. Shafigh), zamin@um.edu.my (M.Z. Jumaat). problems associated with steel plates, fibre reinforced polymer (FRP) was introduced. The use of FRP materials for strengthening has gained considerable attention around the world due to the good durability properties and high strength to weight ratio $[4,6]$. However, FRP strengthened beams have shown a loss in ductility compared to normal unstrengthened beams [7-12]. This reduction in ductility is mainly attributed to the brittle behaviour of the FRP material. In recent years, hybrid FRP materials were introduced and investigated by a number of researchers to overcome the problems of ductility [13-16]. However, the use of hybrid FRP material for strengthening is still limited due to the smal number of reported studies and lack of proper design guidelines $[17,18]$. In addition, the high cost of different FRP materials is another concern.

However, the use of ferrocement laminates has been shown to be an effective and economical method for structural strengthening and retrofitting. Ferrocement laminate consists of different layers of wire mesh embedded in cement mortar. Due to the relatively low flexural strength of cement mortar, the flexural strength of ferrocement laminate is gained entirely from the wire mesh, which 
has a ductile behaviour. The test results by Basunbul et al. [19] showed that RC beams strengthened using ferrocement laminates exhibited an increase in flexural strength and stiffness and an improvement in cracking behaviour. The main problem associated with the use of ferrocement is the separation of ferrocement laminate from the beam soffit. This issue was investigated by Paramasivam et al. [20,21]. The researchers used epoxy adhesive and shear connectors at different spacing to bond the ferrocement laminate to the tension face of beams. In addition, the amount of wire mesh reinforcement in the laminate was varied. It was found that the increase in the flexural capacity of strengthened beams is mainly dependent on the amount of wire mesh reinforcement and maintaining the composite action between the laminate and beam until failure. Furthermore, a study by Al-Kubaisy and Jumaat [22] showed that the use of Hilti bolts and steel bars as shear connectors together with epoxy adhesive maintains a full composite action between the ferrocement laminate and the beam.

Xing et al. [23] used steel wire mesh with polymeric mortar for strengthening reinforced concrete T-beams. A wire mesh with a wire diameter of $3.2 \mathrm{~mm}$ was embedded in polymeric mortar and bonded to the soffit of the beams. The strengthened beams showed an improvement in the flexural capacity and stiffness. However, debonding of the steel-mortar composite was the failure mode in all the strengthened beams, which shows a similar problem to that associated with the ferrocement laminates. Qeshta et al. $[24,25]$ recently developed a new composite for strengthening and retrofitting. The composite consists of the wire mesh commonly used for ferrocement laminates and the epoxy resin. The behaviour of beams bonded with wire mesh-epoxy composite was compared with beams bonded with FRP sheets. It was found that beams bonded with the new composite had superior performance with respect to flexural capacity and energy absorption compared to FRP. In addition, a better ductile and gradual behaviour was achieved with the use of hybrid wire mesh-epoxy-carbon fibre composite. However, the researchers investigated the wire meshepoxy composite on small-scale plain concrete beam specimens. Thus, the aim of this paper is to study the behaviour of large-scale $\mathrm{RC}$ beams strengthened using the wire mesh-epoxy composite. The development of the wire mesh-epoxy composite requires a clear understanding of the behaviour of strengthened RC beams at different loading stages. The type of strengthening material significantly affects the behaviour of the strengthened beam. Therefore, the work presented in this paper is the first step in investigating the effectiveness of using the wire mesh-epoxy composite for strengthening RC structural elements, which helps for further development and making it more practically acceptable. The effect of wire mesh-epoxy composite on load carrying capacity, serviceability and cracking behaviour is investigated and compared with the carbon fibre reinforced polymer (CFRP) and hybrid wire mesh-epoxy-carbon fibre composite. In addition, this paper studies the preparation and development of wire mesh-epoxy composite as a laminate to examine the practical aspect of the application of the composite on site.

\section{Experimental programme}

2.1. Material properties

2.1.1. Concrete and steel

One concrete batch was used to cast all beams. The 28-day average cube compressive strength of concrete, according to BS EN 12390-3:2009 [26], was about $53 \mathrm{MPa}$. The flexural strength, according to BS EN 12390-5:2009 [27], was about 5.30 MPa. The splitting tensile strength was about $4.25 \mathrm{MPa}$. The splitting tensile strength was obtained in accordance with ASTM C496/C496M-11 [28]. In addition, the elastic modulus of concrete was about $39 \mathrm{GPa}$

Three types of steel bar were used for the beam reinforcement. Deformed bars with a diameter of $12 \mathrm{~mm}$ were used for flexural reinforcement while mild steel bars of $8 \mathrm{~mm}$ diameter were used for the stirrup reinforcement. In addition,
Table 1

Mechanical properties of materials used for strengthening.

\begin{tabular}{cllll}
\hline Material & $\begin{array}{l}\text { Ultimate } \\
\text { strength } \\
(\mathrm{MPa})\end{array}$ & $\begin{array}{l}\text { Yield } \\
\text { strength } \\
(\mathrm{MPa})\end{array}$ & $\begin{array}{l}\text { Ultimate strain } \\
\text { (Micro-strain) }\end{array}$ & $\begin{array}{l}\text { Elastic } \\
\text { modulus } \\
(\mathrm{GPa})\end{array}$ \\
\hline $\begin{array}{c}\text { Welded } \\
\text { wire }\end{array}$ & 665.0 & 270.4 & 12000 & 114.2 \\
$\begin{array}{c}\text { mesh } \\
\text { CFRP }\end{array}$ & 4900.0 & $\mathrm{~N} / \mathrm{A}^{\mathrm{a}}$ & 21000 & \\
Epoxy & 30.0 & $\mathrm{~N} / \mathrm{A}^{\mathrm{a}}$ & 9000 & $\begin{array}{l}230.0 \\
\end{array}$ \\
\hline
\end{tabular}

${ }^{a}$ Not applicable.

deformed bars with a diameter of $10 \mathrm{~mm}$ were used as hanger bars for the stirrups. The yield strengths for the 12,10 and $8 \mathrm{~mm}$ bars were 529,521 and $317 \mathrm{MPa}$, respectively. The elastic modulus of 12 and $10 \mathrm{~mm}$ bars was $200 \mathrm{GPa}$ while the $8 \mathrm{~mm}$ bars had an elastic modulus of $210 \mathrm{GPa}$.

2.1.2. Welded wire mesh

The common galvanised welded wire mesh with square openings was used. The mesh had a wire diameter and spacing of 0.64 and $6.4 \mathrm{~mm}$, respectively. The mechanical properties of the wire mesh obtained in accordance with ACl 549.1 R$88[29]$ are shown in Table 1.

2.1.3. CFRP

A unidirectional CFRP sheet was used in this study [30]. The CFRP sheet has a thickness of $0.17 \mathrm{~mm}$. The mechanical properties of CFRP are shown in Table 1.

2.1.4. Epoxy resin

A two-part epoxy impregnation resin was used for fabricating the wire meshepoxy composites [31]. In addition, it was used for bonding the CFRP and wire mesh-epoxy laminate to the beam surface. Table 1 presents the mechanical properties of the epoxy resin.

\subsection{Specimens preparation and strengthening}

The experimental work consisted of one control beam (CB) and four beams strengthened with wire mesh-epoxy composites (specimens A1 and A2) and CFRP (specimen B) as well as a hybrid of wire mesh-epoxy and CFRP (specimen HY), The description of the test specimens is provided in Table 2. The width of the wire mesh-epoxy composite in specimens A1, A2 and HY was $150 \mathrm{~mm}$. Specimens B and HY were strengthened with a $75 \mathrm{~mm}$ width CFRP sheet. The length of strengthening materials in all specimens was $2420 \mathrm{~mm}$.

The study by Qeshta et al. [24] showed that the use of four layers of wire mesh is optimum for increasing the flexural capacity of strengthened specimens. Thus, all the wire mesh-epoxy composites used in this study consisted of four wire mesh layers.

A proper concrete surface preparation was done before applying the strengthening materials. The surface preparation was done in accordance with the manufacturer's instructions for the application of epoxy resin [31]. The surface was first abraded to remove the cement laitance and loose materials that might interfere in the bonding. The dust was then removed using a brush and vacuum air cleaner. Acetone was used to ensure the cleanness of the surface from any material that can affect the bonding.

Two different methods for the application of the wire mesh-epoxy composite were adopted in this study. The wire mesh-epoxy composite in specimen A1 was applied directly on the beam surface. After the surface preparation was completed, a thin layer of epoxy was spread over the surface. This layer helped to fill the small thin layer of epoxy was spread over the surface. This layer hel ped to fill the small the multiple layers of wire mesh were then placed on the concrete surface and the epoxy resin was applied (Fig. 1). It should be mentioned that the amount of epoxy sufficient for bonding the wire mesh was $1.5 \mathrm{~kg} / \mathrm{m}^{2}$ per layer. An acetate release film was placed on the composite to obtain a smooth surface after hardening. A piece of plywood was then placed on the acetate film and clamped to provide good bonding with the surface of the concrete. The composite was left for one week for curing according to the manufacturer's recommendations. After one week, the clamp was finally opened and the acetate film was removed.

In specimens $\mathrm{A} 2$ and $\mathrm{HY}$, the wire mesh-epoxy composite was applied as a laminate. The laminate was prepared away from the beams and applied to their surface after hardening using the same epoxy resin. The main aim of fabricating the laminate was to study the pramitheshthe practically acceptable and less laborious for site application. The laminate was prepared by first applying the epoxy on the layers of the wire mesh placed in a special mould and left one week for curing. After hardening of the composite, the laminate was taken from the mould and prepared for bonding on the soffits of the beams. 
Table 2

Description of test specimens.

\begin{tabular}{ll}
\hline $\begin{array}{l}\text { Beam } \\
\text { designation }\end{array}$ & Strengthening material \\
\hline CB & N/A \\
A1 & $\begin{array}{l}\text { Wire mesh-epoxy composite (applied directly on beam } \\
\text { surface) }\end{array}$ \\
A2 & Wire mesh-epoxy composite laminate \\
B & CFRP sheet \\
HY & A hybrid of wire mesh-epoxy composite and CFRP \\
\hline
\end{tabular}

${ }^{a}$ Not applicable.

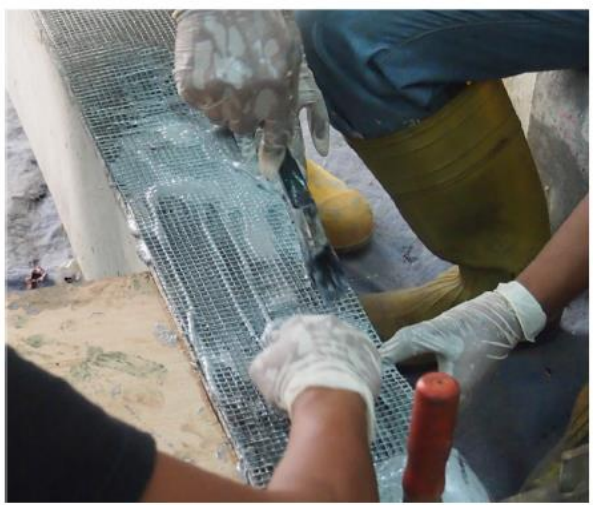

Fig. 1. Applying epoxy on multiple layers of wire mesh placed on beam surface.

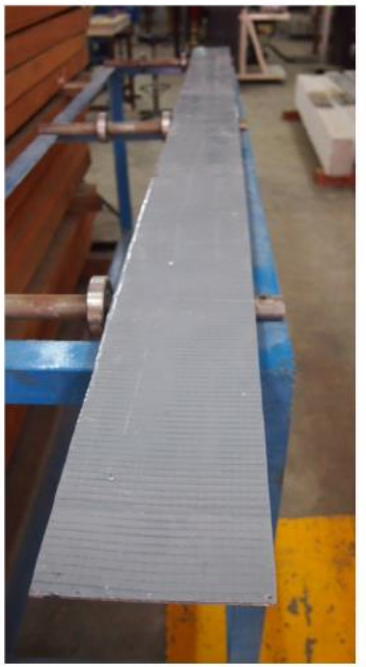

Fig. 2. Wire mesh-epoxy laminate

Fig. 2 shows the wire mesh-epoxy laminate. After completing the preparation of the concrete surface, the epoxy resin was applied on the beam surface followed by the placement of the laminate. Fig. 3 shows the placement of the laminate on the beam surface before clamping. A plywood piece was placed between the laminate and clamping to avoid any local damage on the laminate surface and to distribute the

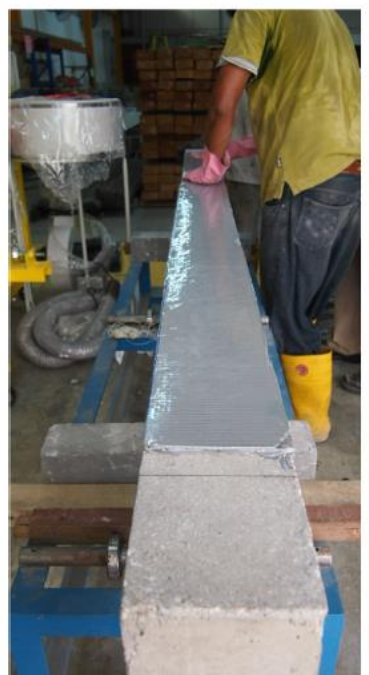

Fig. 3. Placement of the wire mesh-epoxy laminate on beam surface.

pressure evenly over the laminate for perfect bonding. It should be noted that the amount of epoxy found sufficient for bonding the laminate was $0.75 \mathrm{~kg} / \mathrm{m}^{2}$. This amount is similar to that recommended by the manufacturer for bonding one laye of carbon fibre sheet [30,31].

In specimen B, the conventional wet lay-up procedure was used for bonding the CFRP sheet on the beams surface. The epoxy was first spread over the concrete surface followed by placement of the CFRP sheet. A special roller provided by the manufacturer was used to squeeze the resin through the fibres. In specimen HY, both procedures mentioned above for bonding the wire mesh-epoxy laminate and CFRP sheet were applied. The CFRP sheet was applied first on the concrete surface, followed by bonding the wire mesh-epoxy laminate using epoxy resin.

\subsection{Test set-up and instrumentation}

A total of five $\mathrm{RC}$ beam specimens with identical dimensions and reinforcement details were fabricated. Figs. 4 and 5 show the test set-up and beam details. The total length of the beam was $2800 \mathrm{~mm}$. The beam width and depth were 150 and $250 \mathrm{~mm}$, respectively. The beams were singly reinforced with two $12 \mathrm{~mm}$ deforme steel bars. Shear links were provided in the shear span at a spacing of $75 \mathrm{~mm}$ centre-to-centre using $8 \mathrm{~mm}$ mild steel bars. Deformed bars of $10 \mathrm{~mm}$ diameter were trefrom the date of casting. All the beas we failure with an effective span of $2500 \mathrm{~mm}$. The distance between the two poin loads was $700 \mathrm{~mm}$. The mid-span deflection was monitored during the test using a linear variable displacement transducer (LVDT). Strains of the internal steel reinforcement and strengthening materials were monitored using strain gauges. One strain gauge was placed at the centre of each steel reinforcement bar. The strain gauges were placed at the mid-span of the strengthening material and at distances of 300,500 and $1000 \mathrm{~mm}$ from the centre of beam. The distribution of cracks was observed during the test. In addition, the crack widths at the different levels of load were measured using a microscope.

\section{Results and discussion}

\subsection{Load-deflection behaviour}

The load-deflection response of strengthened beams varies significantly depending on the type of strengthening material [32]. This variation provides a useful measure of the performance of strengthened beams. The effectiveness of the wire mesh-epoxy composite, CFRP and hybrid wire mesh-epoxy-carbon fibre composite is evaluated and discussed in the following sections. 


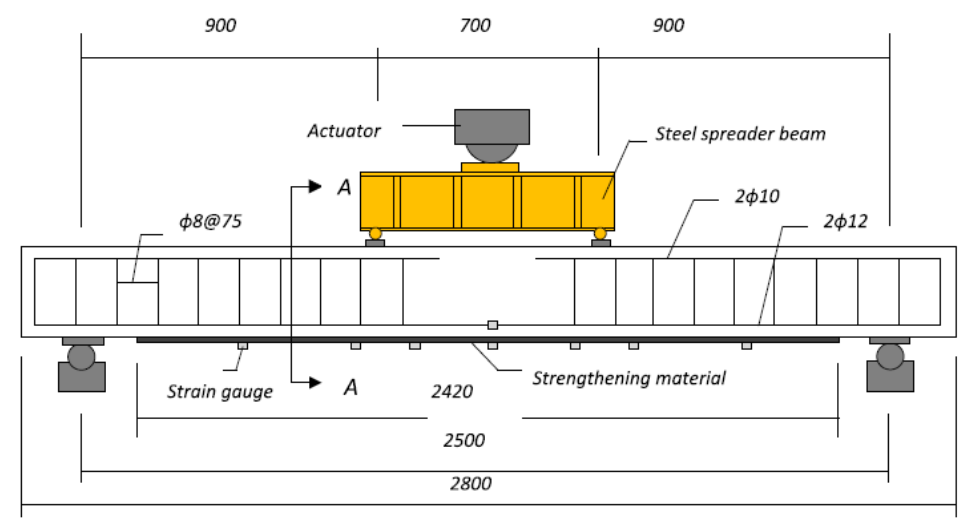

Fig. 4. Test set-up (all dimensions are in $\mathrm{mm}$ ).

3.1.1. Effect of wire mesh-epoxy composite

The load-deflection relationships of the control specimen (CB) and specimens A1 and A2 are shown in Fig. 6. Table 3 summarises the load and deflection values at the first crack, yielding and peak for all specimens. It should be mentioned that specimen A1 was strengthened with wire mesh-epoxy composite applied directly on the beam soffit, whereas specimen A2 was strengthened with the wire mesh-epoxy composite in the form of a laminate. The control specimen failed after the yielding of internal steel reinforcement and concrete crushing in the compression zone. Specimens A1 and A2 failed at two different stages, fracture of wire meshepoxy composite at yield, followed by concrete crushing after a significant increase in the deflection. The load-deflection curves are trilinear defining three distinct stages: the first stage corresponds to the uncracked section and full elastic behaviour of the beam. The load-deflection curve in this stage is almost a straight vertical line representing the full flexural rigidity of the beam. The second stage starts with the initiation of cracks in the tension zone. In this stage, the maximum tensile stresses in the beam exceed the flexural strength of the concrete. Consequently, the beam has a decrease in its flexural stiffness. This can be observed by the reduction in the slope of the load-deflection curve. The third stage includes the yielding of the steel reinforcement. The beam at this stage carries a constant amount of load and shows a significant increase in the deflection up to final failure. The load-deflection curve in this stage is almost flat and the beam is considered to have failed. The first crack appeared in the control beam at a load of $10 \mathrm{kN}$. However, the first crack was observed in beams A1 and A2 at loads of 19 and $18 \mathrm{kN}$, respectively. This shows an increase of up to $90 \%$ over the control beam. The delay in the first crack is mainly attributed to the wire mesh-epoxy composite on the beams soffits. The wire mesh-epoxy composite prevented the initiation of micro-cracks in the vicinity of the beam tension face, and, consequently, prevented the propagation of cracks. The delay of the cracks is of great importance for the serviceability of beams. Maintaining the uncracked section prevents the penetration of water and carbon dioxide from the surrounding environment, which might result in the corrosion of the steel reinforcement. Specimens A1 and A2 showed better stiffness in the post-cracking stage compared to the control specimen. This can be observed from the slope of the load-deflection curve. The load-deflection curves of specimens $A 1$ and $A 2$ are steeper than the control specimen, as shown in Fig. 6. The improvement in stiffness is due to the contribution of the wire mesh-epoxy composite. The wire mesh-epoxy composite restrained the cracks from widening and the beam could carry higher loads without significant loss in stiffness. The control beam yielded at a load of $54 \mathrm{kN}$ as expected. However, beams A1 and A2 exhibited a significant increase in their yield loads, which were 70 and $68 \mathrm{kN}$, respectively. This significant increase is important for achieving the required service loads. The wire mesh-epoxy composite ruptured at the mid-span at slightly higher loads than the yield load. The load-deflection curves of specimens A1 and A2 then showed a drop in load to 57 and $55 \mathrm{kN}$, respectively. These load values are close to that of the control specimen after the yielding load ( $47 \mathrm{kN}$ ). However, the slight increase in load over the control specimen is attributed to the contribution of wire mesh-epoxy composite at the remaining sections of the beam to the overall rigidity. It should be noted that there was no premature debonding between the wire mesh-epoxy laminate and the concrete surface during all loading stages. The composite continued to contribute to the load carrying capacity and stiffness with a full composite action until rupture. Fig. 7 shows the failure of the wire mesh-epoxy composite laminate in specimen A2. The specimens then continued to deflect until final failure by concrete crushing followed by rupture of the steel reinforcement.

By comparing the behaviour of specimens $A 1$ and $A 2$, it was found that the wire mesh-epoxy composite could give the same enhancement to the beams behaviour when applied as a laminate. As a result, the wire mesh-epoxy composite can be prepared and delivered to the site in the form of laminate for easier and more practical strengthening process of structures. In practise, the weight of strengthening materials is an important factor. The calculated density of the wire mesh-epoxy composite laminate was found to be $1627 \mathrm{~kg} / \mathrm{m}^{3}$. The density of mild steel is about $7800 \mathrm{~kg} / \mathrm{m}^{3}$ [33]. This indicates that the density of steel is about five times the density of the wire mesh-epoxy composite laminate. Hence, the wire mesh-epoxy composite laminate has much lighter weight compared to steel plates. This provides easy handling of the strengthening material on site.

\subsubsection{Comparison between the performance of the wire mesh-epoxy} composite and the CFRP

The use of FRP materials for the strengthening and retrofitting of existing RC structures has increased considerably in recent years $[4,6,34]$. Specimen B was strengthened with a $75 \mathrm{~mm}$ wide CFRP sheet. The load-deflection relationships of specimens B, A2 and the control specimen (CB) are shown in Fig. 8. The first crack occurred in specimen $\mathrm{B}$ at a load of $15 \mathrm{kN}$ with an increase of about 


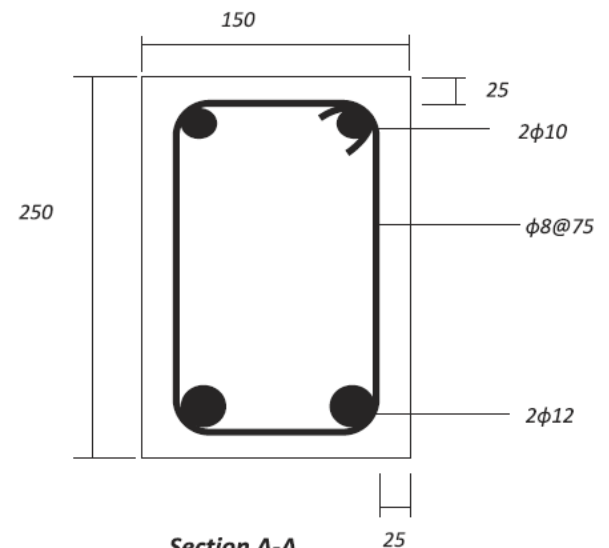

Section A-A

(Control specimen $C B$ )

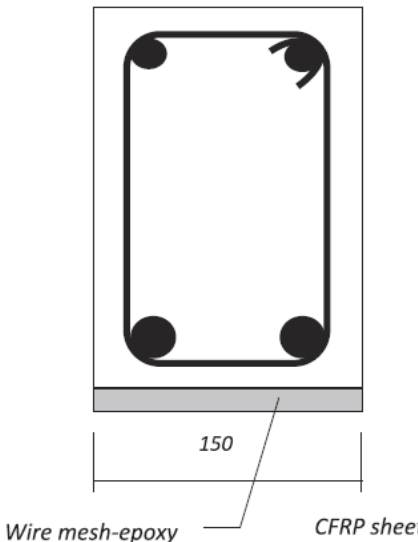

Section A-A

(Specimens $A 1$ and $A 2$ )

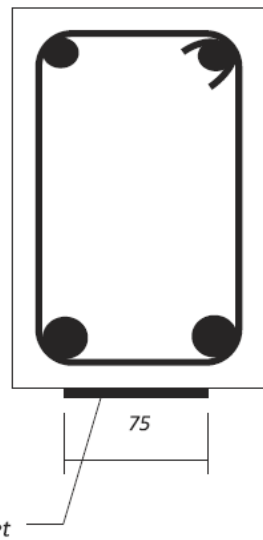

Section A-A

(Specimen B)

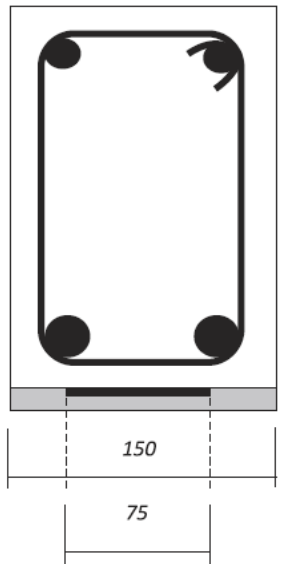

Section A-A

(Specimen $\mathrm{HY}$

Fig. 5. Beam details (all dimensions are in $\mathrm{mm}$ ).

$50 \%$ over the control specimen. The specimen also showed a slight improvement in stiffness after the first crack compared to the control specimen. In addition, the specimen yielded at a load of $58.4 \mathrm{kN}$. This shows an increase of $23 \%$ over the control specimen. A comparison can be made between the behaviour of specimens $A 1$ and $\mathrm{A} 2$ and specimen B. Specimens $\mathrm{A} 1$ and $\mathrm{A} 2$ exhibited an increase in the first crack and yield loads of up to $90 \%$ and $47 \%$, respectively. In addition, the maximum load carrying capacity was achieved at the yielding of the steel reinforcement in specimens A1 and A2. This indicates that a significant enhancement in the behaviour of specimens strengthened with wire mesh-epoxy composite is gained in the pre-yielding stages. This is of great importance for achieving the required increase in load and the delay of cracking for beams under service load. In RC design, the beam is considered structurally failed after the yielding of the steel reinforcement [35]. Therefore, the effectiveness of the strengthening material is always evaluated based on the amount of increase in load prior to the yielding of the steel reinforcement. Specimen B showed a higher ultimate or peak load than specimens A1 and A2. However, this increase in load only occurred after the yielding of the steel reinforcement. This is mainly attributed to the properties of the FRP material. FRP is a brittle material that shows a linear stress-strain behaviour until failure. In addition, the failure strain of CFRP in specimen B is 21,000 microstrains, whereas the yield strain of the tension steel reinforcement is 2700 microstrains. Therefore, the tension steel in specimen B yielded before the CFRP sheet strains, and shows a measurable increase in load. Consequently, CFRP only showed a considerable contribution to the load carrying capacity after yielding. Specimen B continued to deflect significantly after yielding with an increase in load values until reaching the maximum load $(77.6 \mathrm{kN})$. A sudden drop in load to $55.9 \mathrm{kN}$ was then observed at a deflection of 


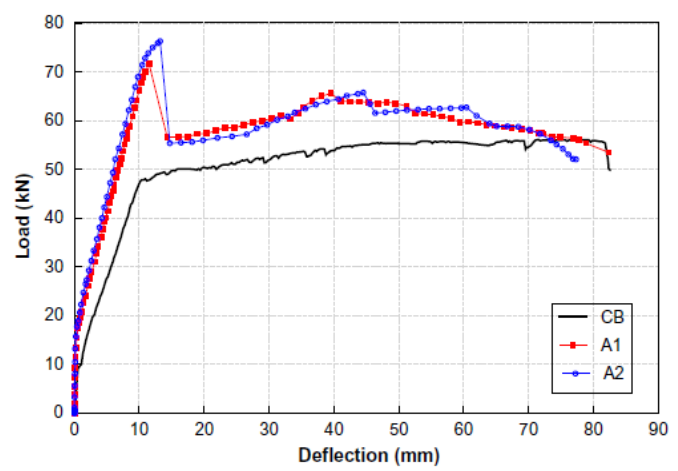

Fig. 6. Load-deflection relationships of specimens $\mathrm{CB}, \mathrm{A} 1$ and $\mathrm{A} 2$.

$34.5 \mathrm{~mm}$. This drop is due to the debonding of the CFRP sheet. Debonding is a common failure mode in beams strengthened with FRP materials [36-38]. Debonding of FRP occurs due to the high stress concentrations at certain regions in the interface between the FRP and the concrete. The stress concentrations are initiated due to the discontinuities of materials and the occurrence of cracks. As a result, a separation propagation path is initiated at the regions of high stress concentration depending on the properties of the strengthening materials and the surface conditions of the concrete. Fig. 9 shows specimen B after the debonding of the CFRP sheet. Debonding is an undesirable failure mode in the structural strengthening, as the FRP material, which has a relatively high cost, cannot be utilised effectively. The specimen continued to deflect after debonding at almost constant load values until final failure. It can be concluded that the wire mesh-epoxy is more efficient in increasing the load-carrying capacity of beams under service compared to CFRP. In addition, the wire mesh-epoxy composite failed by fracture. This indicates that the material was fully utilised for achieving the targeted improvement in the structure load carrying capacity unlike the CFRP, which failed by premature debonding.

3.1.3. Performance of hybrid of wire mesh-epoxy composite and CFRP for strengthening

Specimen HY was strengthened with a hybrid of strengthening materials, namely, a wire mesh-epoxy-carbon fibre composite. Recently, hybrid composite materials have been increasingly used for the strengthening and retrofitting of RC structures [15,39-41]. The load-deflection relationships of specimens HY and CB are presented in Fig. 10. It was shown in the previous sections that the specimens bonded with wire mesh-epoxy composite exhibited a drop in load after yielding due to the fracture of the wire meshepoxy composite. Despite the significant increase in yield load, the specimen did not show a significant enhancement in the load carrying capacity after yielding. In addition, specimen B showed a considerable increase in load carrying capacity only after yielding. The main aim for using the hybrid wire mesh-epoxy-carbon

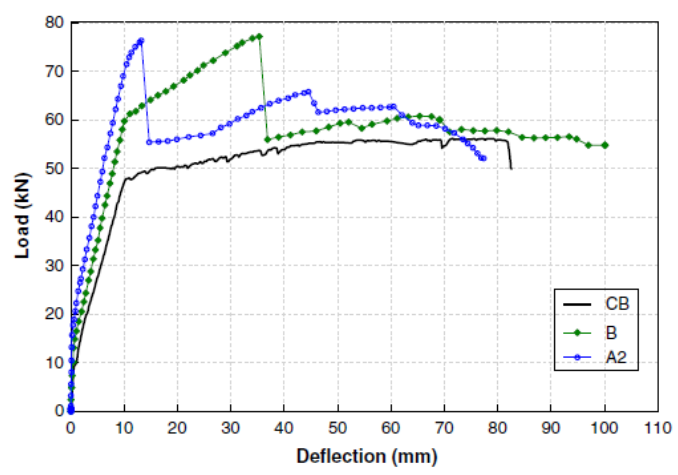

Fig. 8. Load-deflection relationships of specimens B, A2 and CB.

Table 3

Results of tested beams.

\begin{tabular}{|c|c|c|c|c|c|c|c|c|c|c|}
\hline \multirow[t]{2}{*}{ Beam } & \multicolumn{2}{|l|}{ First crack } & \multicolumn{2}{|l|}{$\underline{\text { Yield }}$} & \multicolumn{2}{|l|}{ Peak } & \multicolumn{4}{|c|}{ Mid-span deflection (mm) } \\
\hline & Load $(\mathrm{kN})$ & $\%$ increase & Load $(\mathrm{kN})$ & $\%$ increase & Load $(\mathrm{kN})$ & $\%$ increase & First crack & Yield & Peak & Failure \\
\hline CB & 10.0 & - & 47.5 & - & 56.0 & - & 1.05 & 10.1 & 76.1 & 82.6 \\
\hline $\mathrm{A} 1$ & 19.0 & 90.0 & 70.0 & 47.4 & 72.1 & 29.0 & 0.73 & 12.0 & 12.0 & 82.4 \\
\hline B & 15.0 & 50.0 & 58.4 & 23.0 & 77.6 & 39.0 & 0.82 & 9.7 & 35.0 & 95.5 \\
\hline HY & 16.3 & 63.0 & 70.1 & 47.6 & 82.3 & 47.0 & 1.54 & 13.4 & 20.1 & 74.9 \\
\hline
\end{tabular}

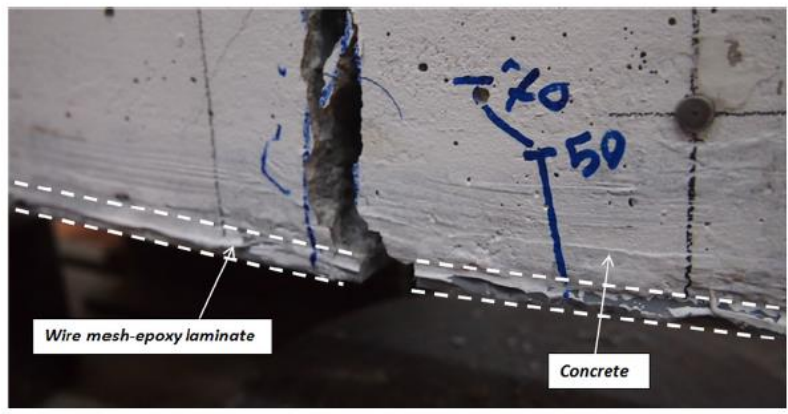

Fig. 7. Failure of wire mesh-epoxy laminate in specimen A2. 


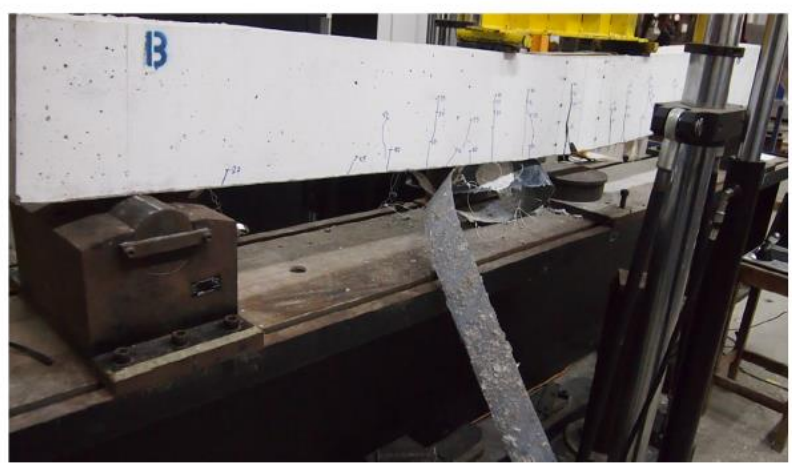

Fig. 9. Debonding of CFRP sheet in specimen B.

fibre composite is to investigate the enhancement of behaviour of strengthened specimens at the overall loading process, i.e. preyield and post-yield stages. Qeshta et al. [24] found that the use of hybrid wire mesh-epoxy with carbon fibre produces progressive failure due to the sequential rupture of materials with different failure strains. Similar to the other strengthened specimens, specimen HY exhibited an increase in the first crack load of up to $16.3 \mathrm{kN}$. The specimen also showed a slight increase in stiffness after the occurrence of the first crack compared to the control specimen. The yield load was increased up to $70 \mathrm{kN}$. This indicates an increase in the first crack and yield loads of $63 \%$ and $47.6 \%$ over the control specimen, respectively.

In comparison with the specimens bonded with wire meshepoxy and CFRP alone, specimen HY exhibited a similar enhancement in yield load. After yielding, the specimen continued carrying increasing loads until $80 \mathrm{kN}$. The wire mesh-epoxy composite then ruptured and a drop in load to $72 \mathrm{kN}$ was observed. This drop in load is more gradual compared to that in the specimens with the wire mesh-epoxy composite alone, which is due to the existence of CFRP sheet. After the rupture of the wire mesh-epoxy composite, the load was totally transferred to the CFRP sheet. As the specimen started to deflect at larger values, the CFRP sheet strained remarkably. Hence, the CFRP sheet started to contribute significantly to the specimen load carrying capacity in the post-yielding stage. It should be noted that small debonding at the mid-span in the wire mesh-epoxy laminate was observed after the rupture, as seen in Fig. 11. The debonding at mid-span is attributed to the loss in

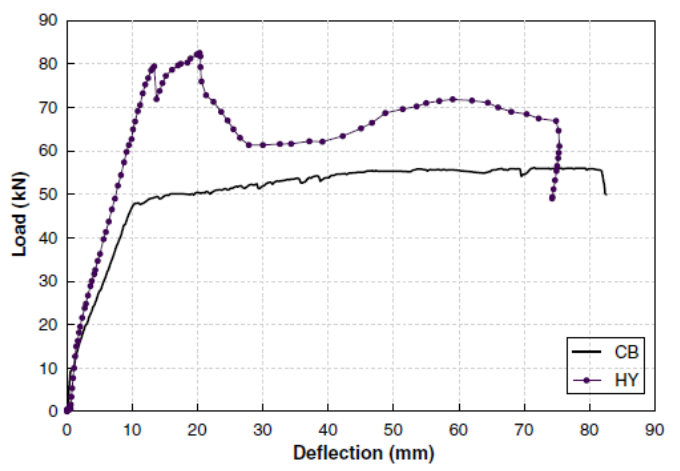

Fig. 10. Load-deflection relationships of specimens HY and CB. composite action between the wire mesh-epoxy laminate and the CFRP sheet. After the rupture of the wire mesh-epoxy composite at yielding, a small slippage at the interface of the wire meshepoxy composite and CFRP sheet occurred. This slippage occurred due to the material relaxation after fracture. Hence, a debonding propagation path started to initiate. However, the propagation did not extend, which was largely due to the strong bonding between the laminate and concrete surface at the sections that are away from the mid-span. Specimen HY carried a load up to $82.3 \mathrm{kN}$. This increase in load is the largest compared to the A1, A2 and B specimens. The CFRP sheet then started to rupture while maintaining higher load values compared to control beam. In addition, The CFRP sheet in specimen HY did not debond like in the case of specimen $\mathrm{B}$. This is attributed to the clamping effect provided by the wire mesh-epoxy laminate. Therefore, the CFRP sheet could be fully utilised for improving the performance of the strengthened specimen. It can be concluded that the use of a hybrid wire mesh-epoxy-carbon fibre composite can significantly provide a better performance of the strengthened specimens at all loading stages compared to the use of wire mesh-epoxy and CFRP alone.

\subsection{Stiffness of the beams}

Stiffness is an essential concern when considering the serviceability behaviour of the RC structures. The stiffness values of al the specimens are presented in Table 4. All the strengthened beams showed significantly more stiffness than the control specimen. However, all the specimens showed a reduction in stiffness after the occurrence of the first crack. Most beams that carry service loads are usually at this stage [35]. Hence, it is important to evaluate the increase in the stiffness of the strengthened specimens at the working load range. The working load range is defined in the load-deflection curve as the point of deflection that is equal to the span/480. This ratio is provided by the ACl 318-11 standard [42] for roofs or floors constructed supporting or attached to nonstructural elements that are likely to be damaged by large deflections. The working load deflection ( $\operatorname{span} / 480$ ) for all beams was found to be $5.2083 \mathrm{~mm}$. As seen in Table 4, all the strengthened specimens exhibited an increase in stiffness at a service load of up to $59.5 \%$ over the control specimen, CB. In normal RC unstrengthened beams, the internal steel reinforcement affects the stiffness of the beam by controlling the growth of the cracks. However, the external bonded material provides restraint to the initiation and growth of the cracks. Specimens A1 and A2, bonded with wire mesh-epoxy composite, showed the largest increase in stiffness compared to the other two specimens (B and HY). In

\section{Link to Full-Text Articles :}

\section{http://www.sciencedirect.com/science/article/pii/S0950061815000264}

